\title{
Heterotopic Gastric Mucosa in the Umbilicus
}

\author{
Young Soo Heo, M.D., Se Yeong Jeong, M.D., Sang Wook Son, M.D., Il-Hwan Kim, M.D., \\ Soo Hong Seo, M.D.
}

Department of Dermatology, College of Medicine, Korea University, Seoul, Korea

Heterotopia refers to the finding of normal tissue in foreign sites, entirely separate from the main organ. Heterotopic gastric mucosa has been observed throughout the alimentary tract, everywhere from the oral cavity to the rectum. However, occurrences in the umbilicus are an extremely rare and peculiar phenomena. We report the case of heterotopic gastric mucosa in the umbilicus. (Ann Dermatol 22(2) 223 225, 2010)

\section{-Keywords-}

Cutaneous, Gastric mucosa, Heterotopia, Umbilicus

\section{INTRODUCTION}

Heterotopic gastric mucosa has the histologic features of gastric mucosa but is situated outside the boundaries of the stomach, anywhere from the mouth to the rectum ${ }^{1}$. There have also been reported cases seen in other areas of the digestive system: in intestinal duplications, Meckel's diverticulum, the gallbladder or cystic duct, the omphalomesenteric duct and the liver ${ }^{2-9}$. Occurrences in the umbilicus, however, are an extremely rare and peculiar phenomena. Following an extensive literature search, we found only 1 case of heterotopic gastric mucosa in the umbilicus.

We report this case of heterotopic gastric mucosa in the umbilical area and our thoughts regarding the cause of this phenomenon.

Received July 18, 2009, Revised August 18, 2009, Accepted for publication September 3, 2009

Corresponding author: Soo Hong Seo, M.D., Department of Dermatology, Korea University Ansan Hospital, 516 Gojan1-dong, Danwon-gu, Ansan 425-707, Korea. Tel: 82-31-412-5180, Fax: 82-31-412-5985, E-mail: drsshong@daum.net

\section{CASE REPORT}

A 5-month-old male patient presented with a pink, erythematous, slowly enlarging, slimy nodule on the umbilicus, present since birth. The infant was born following an uneventful gestational period and had no congenital anomalies.

The umbilical cord dried and fell off at 10 days, however, an erythematous nodule was observed on the umbilical base. Topical electrical cauterization had been performed several times, though the mass continued to grow.

Physical examination showed a dome-shaped, bright red papule with a 1-cm diameter in the umbilical area (Fig. 1). Neither bleeding nor a foul smell was noted.

With a presumed diagnosis of an umbilical granuloma or urachal duct remnant, the patient had received abdominal computed tomography which demonstrated no anomaly. We therefore performed a wide excision of the lesion. Microscopic examination of the excised skin lesion showed a polypoid lesion which was composed of well-developed chief cells, parietal cells, and dilated mucous glands (Fig. 2). Heterotopic gastric mucosa was diagnosed. The patient

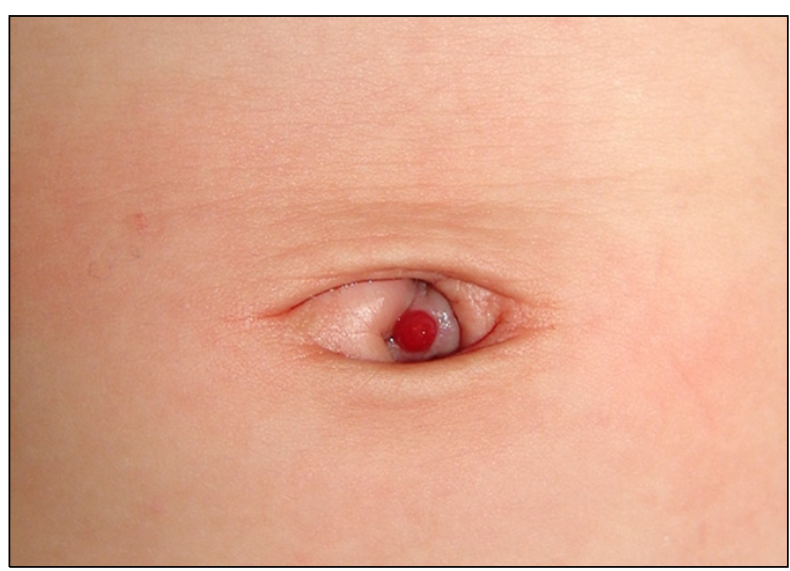

Fig. 1. Pea-sized reddish papule in the umbilicus. 

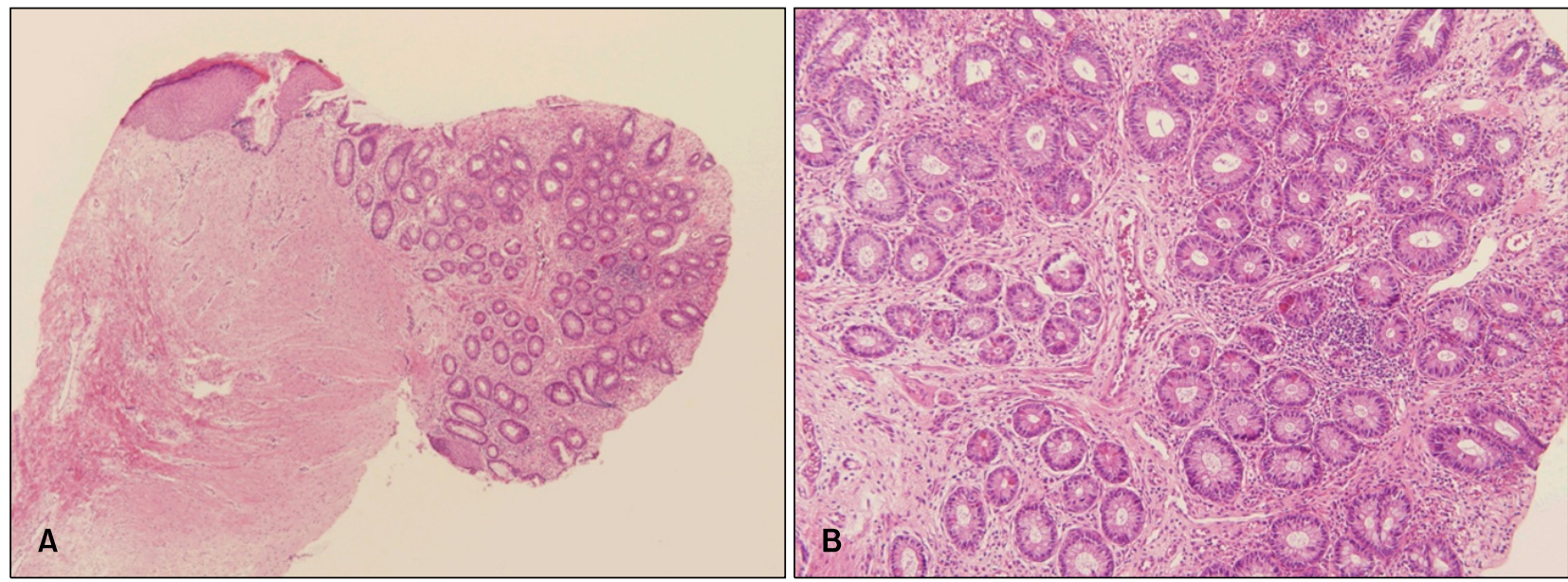

Fig. 2. (A) Multiple small clusters of gastric mucosa glands on pedunculated mass $(H \& E, \times 40)$. (B) Gastric mucosa contain eosinophilc parietal cells adjacent to basophilic chief cells $(\mathrm{H} \& \mathrm{E}, \times 100)$.

had no symptoms for 1 year following the operation.

\section{DISCUSSION}

Umbilical nodules are not rare in infants and young children. The most common cause is umbilical granuloma, which are nodules that vary from benign lesions to severe congenital anomalies. Radiological imaging and a biopsy are therefore needed ${ }^{10}$.

"Heterotopia," derived from Greek, refers to the finding of normal tissue in a foreign site entirely separate from the main organ. Heterotopic gastric mucosa have been observed throughout the alimentary tract, from the oral cavity to the rectum. They have also been seen in intestinal duplications, Meckel's diverticulum, the gallbladder or cystic duct, the omphalomesenteric duct and the liver $^{2-4}$. In addition to the alimentary tract, occurrences in the urinary bladder, the spinal column, the salivary glands, bronchogenic cyst, and the thyroglossal cyst, as well as in intra-abdominal and intra-thoracic locations, have all been noted in literature ${ }^{7-9}$.

Despite an extensive literature search, we found only one other case of gastric heterotopia located in or near the umbilicus. This previous case was heterotopic gastric mucosa and pancreatic tissue in the skin of the abdominal wall ${ }^{5}$.

While there is no clear explanation for the cause of heterotopic tissue growth, it is possible that these growths arise from heteroplastic differentiation, developmental accidents, and metaplastic differentiation ${ }^{11}$. In the gallbladder, it is thought that the fundic-type gastric mucosa occurs as a result of either a developmental anomaly or heteroplastic differentiation, while most pyloric-type gas- tric mucosa occur following metaplastic differentiation ${ }^{12}$. In the head and neck region, a possible mechanism for gastric heterotopia may be developmental errors related to the proximity of the gastric anlage and other fore-gut structures, resulting in the isolation of the gastric mucosa during its morphologic migration ${ }^{13}$.

We postulate the following occurred in our patient: In the developmental process, the mid-gut elongates and herniates into the umbilical cord during the 6th week of embryogenesis. Within the umbilical cord, the mid-gut rotates $90^{\circ}$ counterclockwise around the axis of the superior mesenteric artery, while at the same time elongating to form the jejunum and ileum, and the lumen of the omphalomesenteric duct closes. By the 10th week of embryogenesis, the mid-gut returns to the abdominal cavity $^{14}$. It is at this point in the process when gastric mucosa cells could be seeded in the umbilical area, giving rise to heterotopic gastric mucosa.

We herein report a very rare case of heterotopic gastric mucosa of the skin as well as a possible cause of this phenomenon.

\section{REFERENCES}

1. Langkemper R, Hoek AC, Dekker W, Op den Orth JO. Elevated lesions in the duodenal bulb caused by heterotopic gastric mucosa. Radiology 1980;137:621-624.

2. Gorlin RJ, Kalnins V, Izant RJ Jr. Occurrence of heterotopic gastric mucosa in the tongue. J Pediatr 1964;64:604-606.

3. Martinez-Urrutia MJ, Vasques Estevez J, Larrauri J, Diez Pardo JA. Gastric heterotopy of the biliary tract. J Pediatr Surg 1990;25:356-357.

4. Willis RA. Some unusual developmental heterotopias. $\mathrm{Br}$ Med J 1968;3:267-272. 
5. Dvoracek C. Esophagogastric heterotopia in the skin of the shoulder. Bratisl Lek Listy 1984;82:1271-1278.

6. Shim YT, Kim SY. Heterotopic gastric mucosa and pancreatic tissue in the skin of the abdominal wall. J Pediatr Surg 1992;27:1539-1540.

7. Doberneck RC, Deane WM, Antoine JE. Ectopic gastric mucosa in the ileum: a cause of intussusception. J Pediatr Surg 1976;11:99-100.

8. Kauffman SL, Stout AP. Tumors of the major salivary glands in children. Cancer 1963;16:1317-1331.

9. Wolff $M$. Heterotopic gastric epithelium in the rectum: a report of three new cases with a review of 87 cases of gastric heterotopia in the alimentary canal. Am J Clin Pathol 1971; 55:604-616.
10. Hsu HC, Yang $\mathrm{CH}$, Kuo TT, Shih IH, Hong HS. Urachal duct remnant-like umbilical clear cell acanthoma in an infant: an unusual presentation and pitfall in clinical practice. Int J Dermatol 2007;46:615-618.

11. Hirooka $Y$, Hidano $H$, Sakakibara A, Miyazawa $Y$, Toda N, Matsui $\mathrm{H}$, et al. Heterotopic intestinal membrane in a retroperitoneal tumor. Intern Med 1992;31:782-785.

12. Laitio M. Intestinal, gastric body- and antral-type mucosal metaplasia in the gallbladder. Beitr Pathol 1976;159:271279.

13. Katz A, Aimi K, Skolnik EM. Enterocystoma of the head and neck. Laryngoscope 1980;90:1441-1444.

14. Bauer SB, Retik AB. Urachal anomalies and related umbilical disorders. Urol Clin North Am 1978;5:195-211. 